\title{
Simulation of a solar assisted combined heat pump- Organic Rankine Cycle-system
}

\author{
Stefan Schimpf ${ }^{1, *}$, Karsten Uitz ${ }^{2}$, Roland $\operatorname{Span}^{1}$ \\ ${ }^{1}$ Ruhr-Universität Bochum, Thermodynamics, Bochum, Germany \\ ${ }^{2}$ SIMAKA Energie- und Umwelttechnik GmbH, Argenbühl, Germany \\ * Corresponding author. Tel: +49 2343226390, Fax: +49 2343214163, E-mail: s.schimpf@thermo.rub.de
}

\begin{abstract}
In conventional collector systems for the supply of domestic hot water and space heating the collectors come to a standstill during summer whenever the maximum temperature in the storage tank is reached. The resulting excess heat can be harnessed by a combined heat pump-Organic Rankine Cycle-system. The aim of this work is to simulate such a system in order to determine the optimum operating conditions and impacts on power requirement and cost. For this purpose models for collector, storage tank, heat pump and geothermal heat exchanger are implemented. First results indicate that the isentropic efficiency of the scroll expander has the largest influence on the ORC-revenue. For a system consisting of $12 \mathrm{~m}^{2}$ flat-plate collector area with an expansion efficiency of $\eta_{s, \exp }=0.7$ the power requirement for space heating and domestic hot water is reduced by $3.6 \%$, whereas the costs decrease by $42 €$ or $12.3 \%$ respectively compared to a conventional system. The results suggest that an installation is more reasonable in larger dwelling units like hotels, senior citizens' homes and multiple family dwellings.
\end{abstract}

Keywords: Solar Heating, Organic Rankine Cycle, Heat pump.

\section{Nomenclature}

$A_{c} \quad$ collector aperture area

c coefficients of the characteristic line of the collector

$c_{p, C F} \quad$ isobaric heat capacity of collector fluid ...................................... $\mathrm{kJ} / \mathrm{kgK}$

COP coefficient of performance of the heat pump

$C_{\text {tot }} \quad$ total electricity costs....................... $€$

$E_{H P, D H W}$ electricity consumed by the heat pump for domestic hot water...... $\mathrm{kWh}$

$E_{H P, S H}$ electricity consumed by the heat pump for space heating. $k W h$

$E_{\text {ORC }}$ electricity generated in the ORC. $\mathrm{kWh}$

$E_{\text {tot }} \quad$ total consumed electricity............. $\mathrm{kWh}$

$F^{\prime} \quad$ collector efficiency factor

$G_{b} \quad$ beam radiation ......................W/ $\mathrm{W} / \mathrm{m}^{2}$

$G_{d} \quad$ diffuse radiation .....................W W/ $\mathrm{m}^{2}$

$h \quad$ enthalpy............................. kJ $/ \mathrm{kg}$

$K_{\theta} \quad$ incidence angle modifier ....................

$\dot{m}_{e x} \quad$ external mass flow..................... $\mathrm{kg} / \mathrm{s}$

$\dot{m}_{e x} \quad$ mass flow between nodes .............. kg/s

$n_{\text {ser }} \quad$ number of collectors in series

$\dot{q} \quad$ specific heat flow......................W/ $\mathrm{m}^{2}$

$q_{\text {cond }} \quad$ specific heat of condensation ..... $\mathrm{kJ} / \mathrm{kg}$

$q_{\text {in }} \quad$ supplied specific heat.............. $\mathrm{kJ} / \mathrm{kg}$
$\dot{Q}_{D H W} \quad$ heat transferred to the generation of

$\dot{Q} \quad$ domestic hot water........................W heat loss of a node ........................W conductive heat flow across nodes... W operating time in ORC mode ...........h ambient temperature .................... ${ }^{\circ} \mathrm{C}$ temperature of the ground............. ${ }^{\circ} \mathrm{C}$ temperature of domestic hot water. ${ }^{\circ} \mathrm{C}$ space heating flow temperature ..... ${ }^{\circ} \mathrm{C}$ collector inlet temperature............ ${ }^{\circ} \mathrm{C}$ mean collector temperature ........... ${ }^{\circ} \mathrm{C}$ scroll expander inlet temperature.. ${ }^{\circ} \mathrm{C}$ collector outlet temperature........... ${ }^{\circ} \mathrm{C}$ specific work for compression.... $\mathrm{kJ} / \mathrm{kg}$ specific work of expansion ........ $\mathrm{kJ} / \mathrm{kg}$ volume flow.................................. $l / h$ volume flow per collector string ..... l/h collector slope isentropic compression efficiency isentropic pump efficiency isentropic expansion efficiency density of the collector fluid....... $\mathrm{kg} / \mathrm{m}^{3}$ normal transmittance absorptance product

\section{Introduction}

The application of ground coupled heat pumps and solar combisystems providing both space heating and domestic hot water is a proven technology. In these conventional systems the collectors come to a standstill whenever the maximum temperature in the storage tank is 
reached. However The resulting excess heat can be harnessed in an Organic Rankine Cycle (ORC). The domestic application of an ORC driven by solar heat has been a topic of interest in recent years [1]-[5]. In contrast in this study a scroll expander is applied as expansion device. Advantages of the use of a scroll expander are that no valves have to be used and that their low costs are low because of mass production. The performance of a scroll expander as the expansion device of a Rankine cycle has been investigated by [6]-[8]. In the ORC the working fluid of the heat pump is evaporated by solar heat and is afterwards expanded through the scroll compressor of the heat pump which in this case operates as a scroll expander. When the fluid condenses heat is recharged into the ground increasing the coefficient of performance of the heat pump and potentially reducing the necessary borehole depth. Upgraded controls and a pump for the ORC are the only additionally required investments compared to conventional systems. A schematic drawing of the combined heat pump-ORC system is given in Fig. 1.

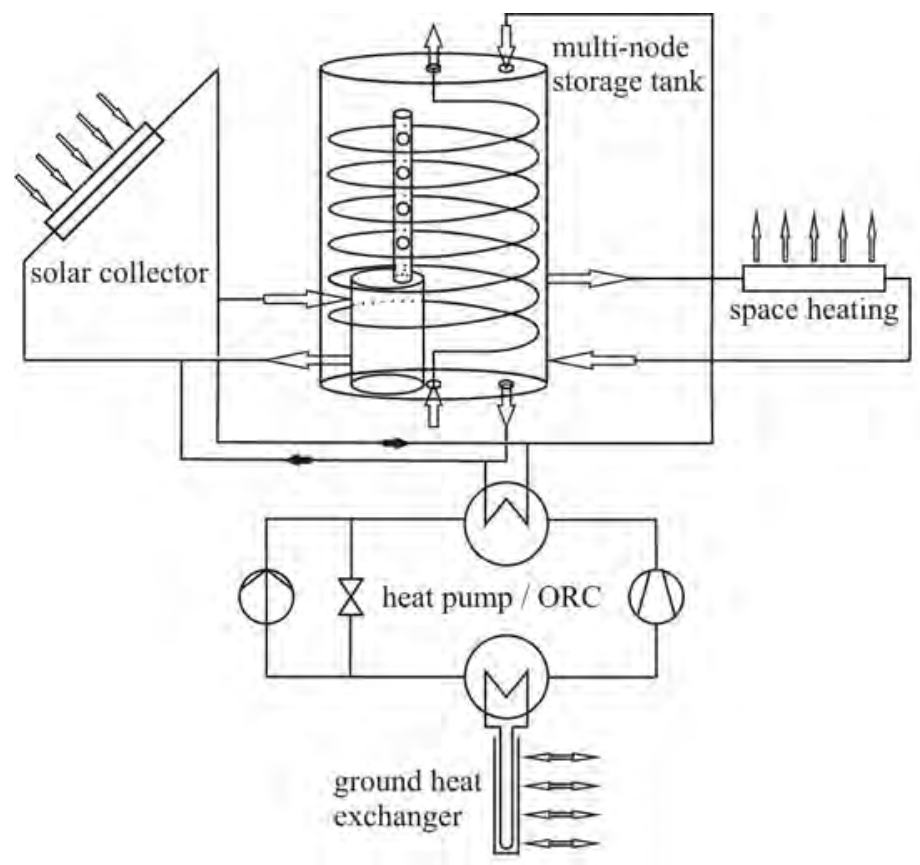

Fig. 1. Schematic drawing of the combined heat pump-ORC system.

\section{Modelling of the components of the combined system}

In order to simulate a combined system models for the solar collector, storage tank, heat pump, Organic Rankine Cycle and geothermal heat exchanger are required. The flat-plate collector has been modelled dynamically by use of a one-node model which is given in the European norm EN 12975 [9]. Dynamic modelling is necessary because the heat capacity of the collector strongly influences the ORC-revenues due to varying heating-up periods for different operating temperatures. The following differential equation Eq. (1) describes the thermal behaviour of a flat-plate collector.

$$
\dot{q}=F^{\prime}(\tau \alpha)_{e n} K_{\theta b}(\theta) G_{b}+F^{\prime}(\tau \alpha)_{e n} K_{\theta d}(\theta) G_{d}-c_{1}\left(T_{m}-T_{a}\right)-c_{2}\left(T_{m}-T_{a}\right)^{2}-c_{5} d T_{m} / d t
$$

The beam and diffuse radiation on the sloped collector have been calculated by means of the algorithms of the European Solar Radiation Atlas [10]. If the collector is feeding the storage tank the volume flow is fixed to a constant value. However if it is operating in ORC mode the volume flow is adjusted to keep a constant temperature. In this case the differential term in 
Eq. (1) is zero and for hourly irradiation data the process can be considered stationary. The resulting volume flow can be calculated by equating Eq. (1) and Eq. (2).

$$
\dot{q}=\rho_{C F} \cdot c_{p, C F} \cdot \dot{V} \cdot\left(T_{o u t}-T_{\text {in }}\right) / A_{C}
$$

The storage tank installed in the combined system is a multi-node storage tank with stratification device. The stratification system ensures the layering of solar heated water at different temperatures which allows for the use of low-temperature solar heat in a s olar combisystem. For each time step a mass and an energy balance have to be solved. It has to be considered that a mass flow also accounts for an energy flow throughout via mixing. The mass and energy flows in a node are depicted in Fig. 2.

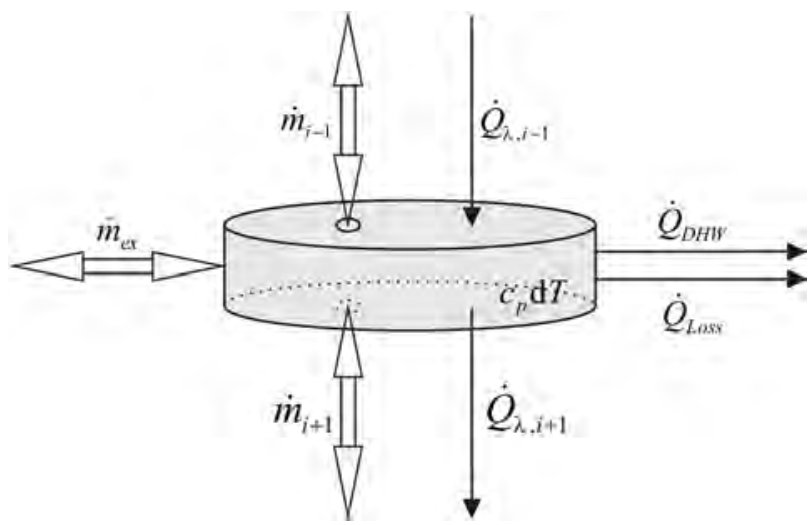

Fig. 2. Mass and energy flow in a node.

Mass flows between adjacent nodes $\left(\dot{m}_{i-1}, \dot{m}_{i+1}\right)$ result from external flows $\left(\dot{m}_{e x}\right)$ of the collector, heat pump or floor heating which are either supplied or removed. The terms $\dot{Q}_{\lambda, i-1}$ and $\dot{Q}_{\lambda, i+1}$ describe the heat conduction between adjacent nodes whereas $\dot{Q}_{D H W}$ marks the heat flow from the node to the coiled tube heat exchanger in which the domestic hot water is generated. $\dot{Q}_{\text {Loss }}$ indicates the heat loss from the storage tank to the ambient. The mass flows are first converted into equivalent heat flows, afterwards the set of differential equations is solved for each node.

All thermodynamic properties required for the simulation of the ORC and the heat pump are calculated with the software Refprop [11]. The terminal temperature differences in heat exchangers are set to $5 \mathrm{~K}$. For the calculation of the COP of the heat pump the upper and lower pressure are the saturation pressures belonging to the temperatures $T_{\text {ground }}$ and $T_{\mathrm{SH}}$ in case of floor heating or $T_{\mathrm{DHW}}$ in case of the generation of domestic hot water. The suction gas is overheated by $3 \mathrm{~K}$ (1a) and afterwards compressed (2a). The compression is assumed to be adiabatic with an isentropic efficiency of $\eta_{s, c}=0.6$. Subsequently the refrigerant condenses (3a) and transfers heat to the floor or water heating system. The refrigerant leaves the condenser as saturated liquid so no s ubcooling is performed. To complete the cycle the pressure is relieved by an expansion valve (4a). The COP of the described process can be calculated with Eq. (3).

$$
C O P=\frac{q_{\text {cond }}}{w_{t, \text { comp }}}=\frac{\left|h_{3 a}-h_{2 a}\right|}{h_{2 a}-h_{1 a}}
$$

For the calculation of the thermal efficiency of the ORC the pressure levels are given through the temperatures $T_{\text {ground }}$ and $T_{\mathrm{ORC}}$. The fluid is compressed by a pump with an isentropic 
efficiency of $\eta_{s, p}=0.6(2 \mathrm{~b})$. Afterwards the fluid is evaporated by heat transfer from the collector fluid (3b). The saturated vapour is expanded in the scroll expander (4b). By default the isentropic efficiency of the expansion is set to $\eta_{s \text {,exp }}=0.5$ which is in good agreement with Peterson et al. [6]. Downstream of the expander the refrigerant is condensed and subcooled by $2 \mathrm{~K}(1 \mathrm{~b})$. The thermal efficiency of this cycle can be calculated as

$$
\eta_{O R C}=\frac{w_{t, \exp }}{q_{\text {in }}}=\frac{\left|h_{4 b}-h_{3 b}\right|}{h_{2 b}-h_{1 b}} .
$$

To model the ground heat exchanger a short time step model is required because the thermal response of the ground is critical for the description of condensation in ORC mode. With the analytical approach of Lamarche and Beauchamp [12] an hourly calculation, which is in good agreement with the short time-step $\mathrm{g}$ functions developed numerically by Yavuzturk and Spitler [13], is achieved.

\section{Simulation and optimisation of the combined system}

In this work a combined heat pump-ORC system has been simulated which is installed in a single family house. The house has a total floor space of $167 \mathrm{~m}^{2}$ and a transmission heat loss of $148.2 \mathrm{~W} / \mathrm{K}$. Both values are characteristically for a 1 ow-energy consumption house fulfilling the German KfW 70 standard. For this type of building a heat pump with a heating output of $5 \mathrm{~kW}$ is sufficient. The simulations were carried out with the refrigerant R134a as working fluid of heat pump and ORC. The simulated system comprises a multi-node storage tank with a volume of 7001 . Six south orientated flat-plate collectors with an aperture area of $2 \mathrm{~m}^{2}$ each are installed in the system. The working fluid of the collectors is a 20/80 propylene glycol-water mixture. The characteristics of both storage tank and collector represent those of commercially available products. Hourly data for the ambient temperature and solar radiation for the climatological station Weihenstephan $\left(48^{\circ} 24^{\prime} \mathrm{N}, 11^{\circ} 42^{\prime}\right.$ E) are taken from the European Solar Radiation Atlas [10]. It is assumed that at 6:30, 7:30, 18:30 and 19:30 in each case 501 of hot water with a temperature of $45^{\circ} \mathrm{C}$ are generated in the coiled tube heat exchanger passing through the storage tank.

The aim of the simulation is to find the optimum configuration of the combined system. For the optimisation the number of collectors in series, the volume flow per string of collectors, the collector slope and the expander inlet temperature of the ORC are varied. The range of these parameters is given in Table 1.

Table 1. Modified parameters for the optimization of the combined system and their range of values.

\begin{tabular}{cc}
\hline Parameter & Range of simulated values \\
\hline Number of collectors in series $n_{\text {ser }}$ & $1-3$ \\
Volume flow per string of collectors $\dot{V}_{\text {str }}$ & $20-801 / \mathrm{h}$ \\
Collector slope $\beta$ & $15-55^{\circ}$ \\
Expander inlet temperature $T_{\mathrm{ORC}}$ & $60-90^{\circ} \mathrm{C}$ \\
\hline
\end{tabular}

Chen et al. [5] simulated a small scale solar-driven carbon dioxide power system and mention the importance of the expansion efficiency as the power output decreases by $60 \%$ for an isentropic efficiency of $50 \%$ instead of $85 \%$. Wang et al. [7] managed to increase the expansion efficiency from $50 \%$ to $70 \%$ by using a compliant expander instead of a kinematically constrained one. In this work it is therefore investigated in how far the efficiency of the expansion influences the ORC output and the overall performance of the 
combined system. For this purpose additional simulations have been done with efficiencies of $\eta_{s, \text { exp }}=0.6$ and $\eta_{s, \exp }=0.7$ instead of the default value of $\eta_{s, \text { exp }}=0.5$.

The output values of the simulation are the electricity consumption of the heat pump for space heating and domestic hot water as well as the power generated in the scroll expander and the power consumption of the pump of the ground loop in the ORC. The power input of the ground loop pump is assumed to be $60 \mathrm{~W}$ and has to be subtracted from the power output of the scroll expander. For the financial evaluation electricity costs are set to $0.2 € / \mathrm{kWh}$ whereas the generated power yields $0.3301 € / \mathrm{kWh}$ under the current German feed-in tariff. All components have been simulated for one year with a time step of one minute except for the ground heat exchanger, which has been calculated on hourly basis. All simulations were performed using Microsoft Visual Basic for Applications scripts

\section{Results}

The results of the simulation show that the energetic optimum of the combined system is reached for collector slopes between $25^{\circ}$ and $35^{\circ}$. The optimum is therefore found for slopes up to $23.4^{\circ}$ lower than the rule of thumb of Duffie and Beckmann [14] proposing surface slopes equal to the latitude. This effect can be explained with the fact that in summer the total irradiation on slopes which are tilted to a lesser extent is higher. This relation which favours the ORC together with the influence of the volume flow on the power output of the ORC and the operating time in ORC mode are displayed in Fig. 3 for a connection of three collectors in series and an expander inlet temperature of $70^{\circ} \mathrm{C}$. The decrease of the ORC power output with increasing volume flow per collector string is due to the shorter operating time in ORC mode. With increasing volume flow lower collector outlet temperatures are achieved and thus the ORC starting temperature is reached less often.

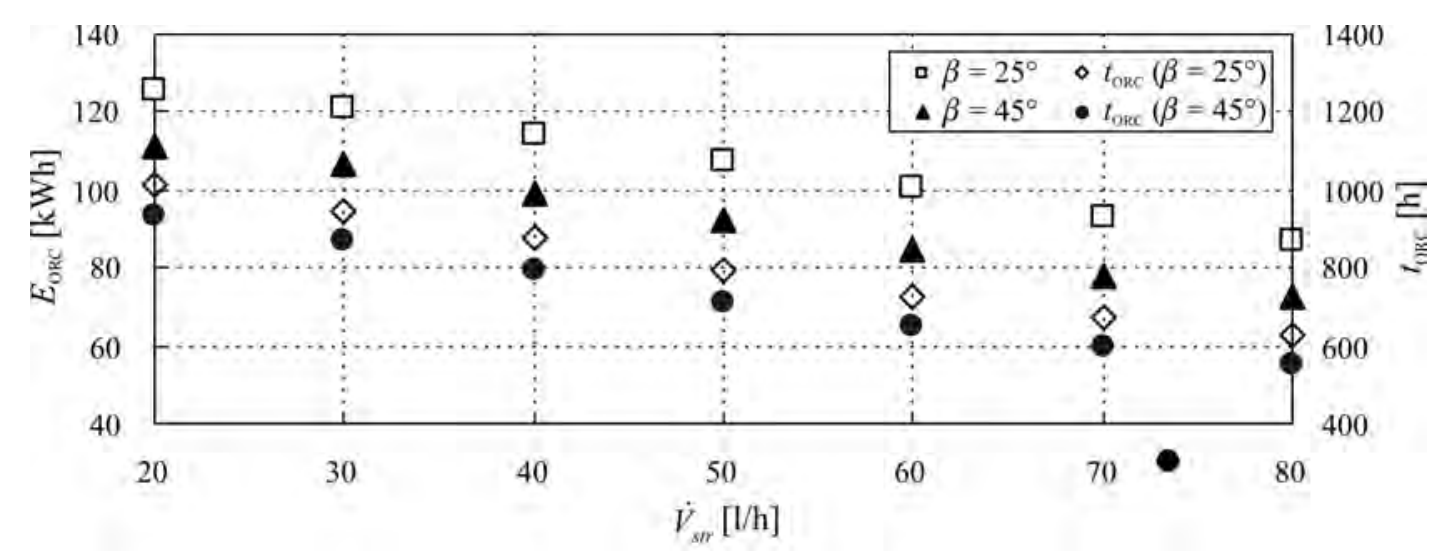

Fig. 3. Influence of the operating time in ORC mode $t_{O R C}$, the volume flow per collector string $\dot{V}_{\text {str }}$ and the collector slope $\beta$ on the ORC power output $E_{\text {ORC }}$ for a connection of three collectors in series and an expander inlet temperature of $70^{\circ} \mathrm{C}$.

The influence of the array configuration, either parallel connection or connection in series, and the specific volume flow per $\mathrm{m}^{2}$ aperture area on the system performance is outlined in Table 2 for a collector slope of $25^{\circ}$ and an expander inlet temperature of $70{ }^{\circ} \mathrm{C}$. Different array configurations (A, B, C) with the same specific volume yield similar output values. The ORC power output is an exception because it decreases with the number of collectors connected in series. The total electricity demand of the combined system however is almost constant. If the volume flow per collector string is held constant and the number of collectors in series is increased (A, D, E) the electricity consumption of the heat pump for space heating $E_{\mathrm{HP}, \mathrm{SH}}$ rises. To reach $T_{\mathrm{SH}}$ a rather low irradiance is required and the operating time in space 
heating mode is quite high. As a consequence the operating time is rising to a lesser extent than the solar gain is dropping because of the lower volume flow. In contrast the electricity consumption of the heat pump for the generation of domestic hot water is reduced and the ORC power output is increased because higher operating temperatures are reached more often and faster for smaller specific volume flows.

Table 2. The effect of the array configuration and the specific volume flow per $m^{2}$ aperture area on the annual electricity consumption of the heat pump for space heating $E_{H P, S H}$ and domestic hot water $E_{H P, D H W}$ as well as the ORC power output $E_{O R C}$ and the total power consumption $E_{\text {tot }}$ for a collector slope of $25^{\circ}$ and an expander inlet temperature of $70^{\circ} \mathrm{C}$.

\begin{tabular}{cccccccc}
\hline Case & $n_{\text {ser }}$ & $\begin{array}{c}\dot{V}_{\text {str }} \\
{[1 / \mathrm{h}]}\end{array}$ & $\begin{array}{c}\dot{V}_{\text {str }} /\left(n_{\text {ser }} \cdot A_{\mathrm{c}}\right) \\
{\left[1 / \mathrm{m}^{2} \mathrm{~h}\right]}\end{array}$ & $\begin{array}{c}E_{\mathrm{HP}, \mathrm{SH}} \\
{[\mathrm{kWh}]}\end{array}$ & $\begin{array}{c}E_{\mathrm{HP}, \mathrm{DHW}} \\
{[\mathrm{kWh}]}\end{array}$ & $\begin{array}{c}E_{\mathrm{ORC}} \\
{[\mathrm{kWh}]}\end{array}$ & $\begin{array}{c}E_{\text {tot }} \\
{[\mathrm{kWh}]}\end{array}$ \\
\hline $\mathrm{A}$ & 1 & 20 & 10 & 1261.6 & 611.2 & 113.4 & 1759.4 \\
$\mathrm{~B}$ & 2 & 40 & 10 & 1260.1 & 612.4 & 102.8 & 1769.7 \\
$\mathrm{C}$ & 3 & 60 & 10 & 1258.7 & 599.2 & 100.3 & 1757.6 \\
\hline $\mathrm{D}$ & 2 & 20 & 5 & 1303.6 & 598.0 & 123.5 & 1778.1 \\
$\mathrm{E}$ & 3 & 20 & 3.33 & 1354.1 & 536.5 & 125.9 & 1764.7 \\
\hline
\end{tabular}

For the cases A, B and C given in Table 2 the influence of the isentropic expansion efficiency on the expander power output has been investigated. The results are illustrated in Fig. 4 together with the thermal efficiency of an Organic Rankine Cycle with the assumptions made in section 3 , an evaporation temperature of $70^{\circ} \mathrm{C}$ and a condensing temperature of $20^{\circ} \mathrm{C}$. If the power consumed by the ground loop pump is subtracted from the values depicted in Fig. 4 the same values for the power output of the ORC as in Table 2 are obtained for $\eta_{s, \text { exp }}=0.5$.

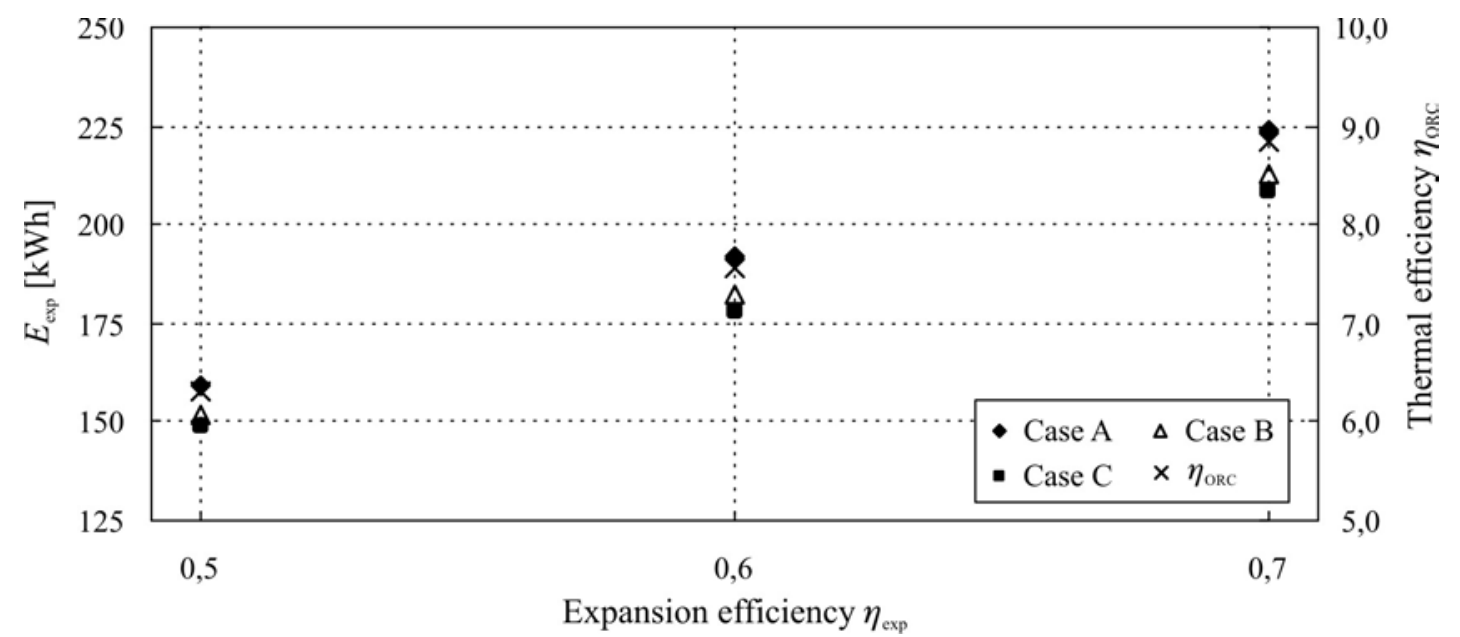

Fig. 4. Influence of the expansion efficiency $\eta_{s, e x p}$ on the thermal efficiency of the ORC $\eta_{\text {ORC }}$ and the expander power output $E_{\text {exp }}$ for different array configurations with the same specific volume flow.

Fig. 4 shows that the thermal efficiency of the ORC $\eta_{O R C}$ is the only variable influencing the expander output power. If the efficiency of the expansion is increased by ten percentage points the expander output power and $\eta_{O R C}$ grow by about $20 \%$. This result is in agreement with the course determined by Chen et al. [5]. With rising thermal efficiency a negligible lower amount of heat is recharged into the ground which would influence the electricity consumption of the heat pump. As the thermal efficiency has no effect on the operating time of the ORC, the power consumption of the ground loop pump remains constant. The results of the simulation reveal that all output values except for the power output remain almost unaffected by the expansion efficiency which has been expected. 
Finally the optimised system configurations for each expander efficiency are compared with a conventional system from an energetic and financial point of view. The conventional system is simulated using the methods and assumptions presented in section 2 and section 3 just without the ORC mode. The simulation results for each optimised system and the conventional system are outlined in Table 3.

Table 3. Comparison of the electricity consumption and cost of a conventional solar combisystem and optimised system configurations of the combined heat pump-ORC system for different isentropic scroll expander efficiencies.

\begin{tabular}{cccccccccc}
\hline$\eta_{\text {s,exp }}$ & $n_{\text {ser }}$ & $\begin{array}{c}\dot{V}_{\text {str }} \\
{[1 / \mathrm{h}]}\end{array}$ & $\begin{array}{c}\beta \\
{\left[{ }^{\circ}\right]}\end{array}$ & $\begin{array}{c}T_{\text {ORC }} \\
{\left[{ }^{\circ} \mathrm{C}\right]}\end{array}$ & $\begin{array}{c}E_{\text {tot }} \\
{[\mathrm{kWh}]}\end{array}$ & $\begin{array}{c}\Delta E_{\text {tot }} \\
{[\%]}\end{array}$ & $\begin{array}{c}\text { ORC- } \\
\text { revenue } \\
{[€]}\end{array}$ & $\begin{array}{c}\text { Total } \\
\text { costs } C_{\text {tot }} \\
{[€]}\end{array}$ & $\begin{array}{c}\Delta C_{\text {tot }} \\
{[\%]}\end{array}$ \\
\hline- & 2 & 30 & 35 & - & 1729.3 & - & - & 346.1 & - \\
\hline 0.5 & 1 & 40 & 35 & 60 & 1717.4 & -0.7 & 30.2 & 328.6 & -5.1 \\
0.6 & 1 & 40 & 25 & 60 & 1693.0 & -2.1 & 41.2 & 319.1 & -7.8 \\
0.7 & 1 & 30 & 25 & 60 & 1665.1 & -3.6 & 53.7 & 308.6 & -10.8 \\
\hline 0.5 & 1 & 30 & 25 & 60 & 1719.5 & -0.6 & 35.8 & 326.3 & -5.7 \\
0.6 & 3 & 20 & 25 & 70 & 1727.3 & -0.1 & 61.9 & 316.3 & -8.6 \\
0.7 & 3 & 20 & 25 & 70 & 1689.9 & -2.3 & 74.2 & 303.9 & -12.3 \\
\hline
\end{tabular}

The results indicate that the energetic and financial optima are reached for different system configurations. The relative cost savings exceed the energy savings which is due to the fact that $1 \mathrm{kWh}$ generated electricity equals $1.65 \mathrm{kWh}$ consumed electricity because of the feed-in tariff. The energetic optima are reached for a parallel connection of collectors. The rather low energy savings can be explained with the fact that in the combined system the storage tank is charged with less solar heat than in a conventional system. However the combined system is still superior in comparison. For higher expansion efficiencies the array configurations with the lowest specific volume flow become attractive from a financial standpoint as a consequence of the greater ORC revenues.

\section{Conclusion}

In this work annual simulations of a solar assisted combined heat-pump ORC system have been performed. The results indicate that this system is superior to a conventional solar combisystem from an energetic and financial standpoint. The annual savings strongly depend on the efficiency of the expansion. For a small combined system with a flat-plate collector area of $12 \mathrm{~m}^{2}$ the relative energetic savings range from $0.7 \%\left(\eta_{s, \exp }=0.5\right)$ to $3.6 \%$ $\left(\eta_{s, \text { exp }}=0.7\right)$. The absolute monetary savings are about $20 €$ for $\eta_{s, \text { exp }}=0.5$. They rise to $42 €$ for an increased efficiency of $\eta_{s, \exp }=0.7$. It therefore seems possible to cover the additional costs that arise from an ORC pump and advanced controls. As the costs for the controls are independent of the system size an application of the combined system is more reasonable in larger dwelling units like hotels, senior citizens' homes and multiple dwelling houses. Experimental studies to evaluate the efficiency of the scroll compressor in expansion mode are required. The results of this study concerning collector slope and volume flow can also be transferred to future works regarding solar-driven Organic Rankine Cycles.

\section{Acknowledgements}

The authors would like to thank the Federal Ministry of Economics and Technology for financially supporting this work. 


\section{References}

[1] J L. Wolpert; S. B. Riffat, Solar-powered Rankine system for domestic applications, Applied Thermal Engineering 16, 1996, pp. 281-289.

[2] C.-H. Kuo; W.-J. Yang; N. Arai; K. Mori, Solar-powered organic Rankine system for domestic electric-power generation, Energy and the environment: Proceedings of the Second Trabzon International Energy and Environment Symposium, 1999, pp. 67-74.

[3] A. Delgado-Torres; L. Garcia-Rodriguez, Analysis and optimization of the lowtemperature solar organic Rankine cycle (ORC), Energy Conversion and Management 51, 2010, pp. 2846-2856.

[4] X. R. Zhang; H. Yamaguchi; K. Fujima; M. Enomoto; N. Sawada, Theoretical analysis of a thermodynamic cycle for power and heat production using supercritical carbon dioxide, Energy 32, 2007, pp. 591-599.

[5] Y. Chen; W. Pridasawas; P. Lundqvist, Dynamic simulation of a solar-driven carbon dioxide transcritical power system for small scale combined heat and power production, Solar Energy 84, 2010, pp. 1103-1110.

[6] R. B. Peterson; H. Wang; T. Herron, Performance of a small-scale regenerative Rankine power cycle employing a scroll expander, Proceedings of the Institution of Mechanical Engineers/ Part A, Journal of power and energy 222, 2008, pp. 271-282.

[7] H. Wang; R. B. Peterson; T. Herron, Experimental performance of a compliant scroll expander for an organic Rankine cycle, Proceedings of the Institution of Mechanical Engineers/ Part A, Journal of power and energy 223, 2009, pp. 863-872.

[8] T. Saitoh; N. Yamada; S. Wakashima, Solar Rankine Cycle System Using Scroll Expander, Journal of Environment and Engineering 2, 2007, pp. 708-718.

[9] EN 12975, T hermal solar systems and components - Solar collectors - Part 2: Test methods, 2006.

[10]K. Scharmer; J. Greif, The European solar radiation atlas, Les Presses de L'École des Mines, $1^{\text {st }}$ Edition, 2000.

[11]E. W. Lemmon; M. O. McLinden; M. L. Huber, NIST Reference Fluid Thermodynamic and Transport Properties - REFPROP. NIST Standard Reference Database 23, Version 8, 2002.

[12]L. Lamarche; B. Beauchamp, A fast algorithm for the simulation of GCHP systems, ASHRAE Transactions 113, 2007, 470-476.

[13]C. Yavuzturk; J. D. Spitler, A short time step response factor model for vertical ground loop heat exchangers, ASHRAE Transactions 105, 1999, 475-485.

[14]J. A. Duffie; W. A. Beckman, Solar Engineering of Thermal Processes, Jon Wiley \& Sons, $2^{\text {nd }}$ Edition, 1980 , pp. 98-101. 